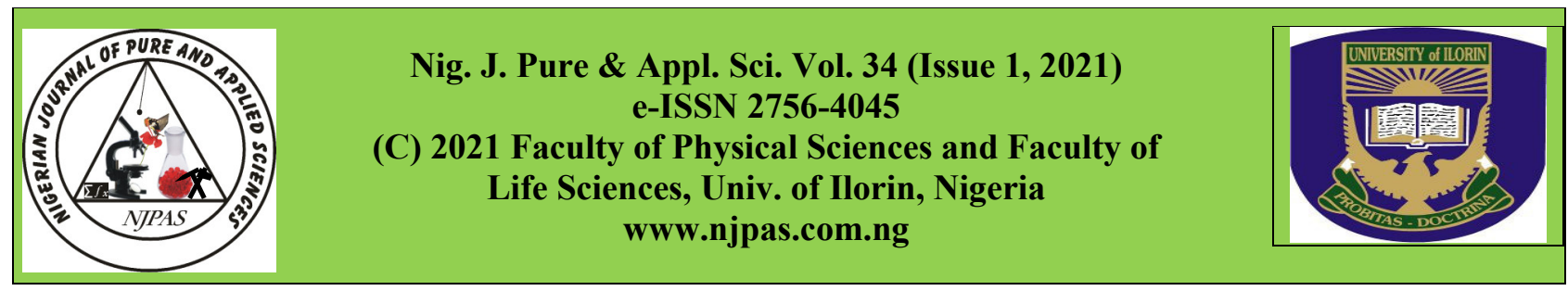

\title{
http://dx.doi.org/10.48198/NJPAS/19.B25
}

\section{Sonographic Evaluation of Liver Dimensions among Apparently Healthy Adult Subjects in Kano Metropolis}

\section{ABSTRACT}

The ability to ascertain the human liver by a sonographer allows for the diagnosis of various liver pathologies, establishing normal liver size aids in determining the treatment method for the underlying liver pathology. The study was aimed at evaluating normal liver size among apparently healthy adult subjects and to establish a reference value in Kano Metropolis. The study design was prospective and cross-sectional conducted in Kano Metropolis from June 2019 to September 2019. Using simple random sampling, a total of 384 subjects were recruited in the study. An EDAN ultrasound machine with a $3.5 \mathrm{MHz}$ curvilinear probe was used as the instrument for data collection. Age, height, weight, BMI and BSA were recorded on a data capture sheet. Data was analyzed by SPSS version 23.0. The mean $( \pm \mathrm{SD})$ for cranio-caudal dimension of the right lobe was found to be $14.99 \pm 0.74 \mathrm{~cm}$ in males and $14.38 \pm 0.72 \mathrm{~cm}$ in females, mean left lobe $5.76 \pm 0.85 \mathrm{~cm}$ in males and $5.39 \pm 0.81 \mathrm{~cm}$ in females. The mean AP diameter of the right lobe was $13.02 \pm 1.12 \mathrm{~cm}$ in males and $12.34 \pm 0.95 \mathrm{~cm}$ in females. Liver dimension in males was greater than that of females $(\mathrm{p}<0.001)$. Age and weight show significant moderate correlations with liver dimensions. $(r=0.52, p<0.001$ and $r=0.44, p<0.001)$ in both males and females respectively. In Kano Metropolitan population, liver size was greater in males than females. It correlates significantly with age and weight in both males and females.

Keywords: Sonographic, liver dimension, Mid-clavicular Line, Kano Metropolis

\section{Introduction}

The liver is the largest abdominal organ in the human body. It weighs approximately $1500 \mathrm{~g}$ and is located in the right upper quadrant of the abdomen (Moore, 2013). The liver performs various essential functions which include; metabolism of carbohydrates, proteins and lipid, production of bile that help in the digestion process, detoxification function and storage of vitamins (Barrett, 2012). Various pathological processes may result in either alterations in the size or shape of the liver (Odegaard, 2005). An increased in size beyond normal is termed hepatomegaly which is linked with various disease conditions which includes inflammatory conditions, fatty infiltration, neoplasms, polycystic liver diseases (Ahmad and Tahir, 2012) high venous pressure causing congestion metabolic diseases and dilated hepatic sinusoids(Childs, 2014). On the other hand reduced liver size may be associated to liver cirrhosis and acute fulminant hepatitis (Singh, 2017). Ultrasound is a real-time, rapid, available and inexpensive technique to evaluate the size of the adult liver and the patient is not exposed to 
ionizing radiation (Singla et al., 2017). Doppler ultrasound can provide important information on the hemodynamics of the portal venous system (Kok et al., 1999).The variations in anthropometric feature of a diverse population, Page | 3858 geography, race and region are established fact (Mittal, 2010). In a study conducted by Ozmen et al. (2018) in Turkey, liver sizes were found to be $(150.04 \pm 14.84 \mathrm{~mm})$ in males and $(147.57 \pm$ $18.32 \mathrm{~mm})$ in females. A study conducted by Singh, (2017) in India, the mean liver span in males to be $(14.16 \mathrm{~cm} \pm 1.32 \mathrm{~cm})$ and $(12.79 \mathrm{~cm} \pm$ $1.40 \mathrm{~cm}$ ) in females. In another study conducted by Kratzer et al (2003) in Germany, the average liver length in male subjects was $(14.5 \pm 1.6$ $\mathrm{cm})$ and $(13.5 \pm 1.7 \mathrm{~cm})$ in female subjects. There is a paucity of data on normal measurement of liver dimension by ultrasonography in Kano Metropolis. The ranged values of AP diameter of right and left lobes and cranio-caudal dimension of $10.58-15.72 \mathrm{~cm}, 3.57-7.60 \mathrm{~cm}$ and $13.10-16.49$ $\mathrm{cm}$ for males and $9.66-14.95 \mathrm{~cm}, 3.28-7.72 \mathrm{~cm}$ and 12.65-15.94 $\mathrm{cm}$ for females will serve as a guide for sonographers, radiologists and physician in patient diagnosis and management. The study was aimed at evaluating sonographic liver dimensions in apparently normal adult subjects in Kano metropolis.

\section{Materials and Methods}

The study design was cross sectional and prospective carried out at some selected hospitals including Murtala Muhammad Specialist Hospital, Aisami Primary Health care and Sheka primary Health care located at different areas of Kano Metropolis from June 2019 to September 2019. The study was approved by the research and ethics committee, Ministry of Health, Kano State and informed consent was obtained from all the subjects. Using a random sampling, a total of 384 subjects were recruited for the study obtained using Cochran formula. Thus;

$$
n=\frac{Z^{2} p q}{d^{2}}
$$

Where $\mathrm{n}=$ minimum sample size?

$\mathrm{z}=$ percentage point of distribution at $95 \%$ confidence interval (1.96)

$\rho=$ prevalence from other previous study $=50 \%$ $(0.5)$

$\mathrm{q}=1-\mathrm{p}($ complimentary probability $)=0.5$

$\mathrm{d}=$ maximum sample error $=5 \%(0.05)$ using the above data the sample size was

$\mathrm{n}=(1.96)^{2 * 0.5 * 0.5 /(0.05)^{2}}$

$\mathrm{n}=3.8416 * 0.25 / 0.0025$

$\mathrm{n}=0.9604 / 0.0025$

$\mathrm{n}=384$

Ages ranged 18-65 years. All the selected subjects do not have any history of alcohol consumption, diabetes, liver related abnormality such as cardiac failure, inflammatory disease and neoplasms and pregnant women because of the physiological hypertrophy associated with pregnancy. The age, height, weight, Body Mass Index (BMI) and Body Surface Area (BSA) were recorded on a data capture sheet, sonographic evaluation was done using EDAN D3/DUS3 and ZONECARE ZQ6602 ultrasound machines each having a convex array probe with $3.5 \mathrm{MHz}$ frequency. The liver dimensions were measured from the dome of the diaphragm to the tip of the right hepatic lobe as described by (Kratzer et al., 2003), the Anteroposterior diameter was measured as described by (Niederau et al., 1983) and the left lobe was also measured based on the method adopted by (Mittal, 2010).Data was analysed using statistical package for social sciences (SPSS version 23.0). The preset $\rho$ value was $(\leq 0.05)$ that is, at $95 \%$ confidence interval.

\section{Results}

Data from 384 subjects was assessed of which $50 \%(\mathrm{n}=192)$ were male subjects, remaining $50 \%$ $(n=192)$ were female subjects, the 
(Mean \pm Standard deviation and range) values of the anthropometric variables (Height, weight, BMI and BSA) for both genders are shown in Table 1. It shows the mean age, height, weight, BMI, BSA and the standard deviation of the male selected Page | 3859 subjects was $36.65 \pm 12.55$ years, $168.08 \pm 7.79 \mathrm{~cm}$, $69.32 \pm 12.23 \mathrm{Kg}, 24.53 \pm 3.99 \mathrm{Kg} / \mathrm{m}^{2}$ and $1.79 \pm$ $0.17 \mathrm{~m}^{2}$, while that of the female subjects were $26.90 \pm 8.17$ years, $159.84 \pm 5.86 \mathrm{~cm}$, $60.61 \pm 14.65 \mathrm{Kg}, 23.66 \pm 6.10 \mathrm{Kg} / \mathrm{m}^{2}$ and $1.62 \pm$ $0.23 \mathrm{~m}^{2}$. Mean values of all the variables are greater among males than females. The mean dimensions of the liver (cranio-caudal, AP diameter of the right lobe and AP diameter of the left lobe) are greater in male subjects than female subjects as shown in Table 2. The mean AP diameter of the right and left liver lobes and cranio-caudal dimension and the standard deviation of the male selected subjects were $13.02 \pm 1.12 \mathrm{~cm}, 5.76 \pm 0.85 \mathrm{~cm}$ and $14.99 \pm 0.74 \mathrm{~cm}$, while that of the female subjects were $12.34 \pm$ $0.95 \mathrm{~cm}, 5.39 \pm 0.81$ and $14.38 \pm 0.72 \mathrm{~cm}$.

There are statistically significant differences in all the liver measurements between genders $(\rho<0.05)$ as shown in Table 3. The Correlation between liver dimensions and anthropometric variables in male and female subjects are shown in Table 4 and 5 respectively, age and weight in both genders showed significant positive correlation than height, BMI and BSA.

Table 1: Demographic information of the selected subjects, the Mean \pm SD and range

\begin{tabular}{|c|c|c|c|c|c|}
\hline \multirow{2}{*}{ Gender } & \multicolumn{5}{|c|}{ Demographic Variables } \\
\hline & Age (years) & Height(cm) & Weight(Kg) & ВMII $\left(\mathrm{Kg} / \mathrm{m}^{2}\right)$ & $\operatorname{BSA}\left(\mathrm{m}^{2}\right)$ \\
\hline Males & $\begin{array}{c}36.65 \pm 12.55 \\
(18-65)\end{array}$ & $\begin{array}{c}168.08 \pm 7.79 \\
(114-190)\end{array}$ & $\begin{array}{c}69.32 \pm 12.23 \\
(40-110)\end{array}$ & $\begin{array}{c}24.53 \pm 3.99 \\
(15.70-38.57)\end{array}$ & $\begin{array}{c}1.79 \pm 0.17 \\
(1.13-2.40)\end{array}$ \\
\hline Females & $\begin{array}{c}26.90=8.17 \\
(18-55)\end{array}$ & $\begin{array}{c}159.84=5.86 \\
(147-175)\end{array}$ & $\begin{array}{c}60.61=14.65 \\
(32-107)\end{array}$ & $\begin{array}{c}23.66 \pm 6.10 \\
(0.0-44.3)\end{array}$ & $\begin{array}{c}1.62=0.23 \\
(0.0-2.18)\end{array}$ \\
\hline
\end{tabular}

Table 2: Mean, Standard Deviation and range values of the AP diameter of the right and left lobes and cranio-caudal dimensions in male and female selected subjects

\begin{tabular}{lccc}
\hline & \multicolumn{3}{c}{ Liver dimensions } \\
\cline { 2 - 4 } Gender & Right lobe(cm) & Left lobe(cm) & Cranio-caudal(cm) \\
\hline \multirow{2}{*}{ Males } & & & \\
& $13.02 \pm 1.12$ & $5.76 \pm 0.85$ & $14.99 \pm 0.74$ \\
& $(10.58-15.72)$ & $(3.57-7.60)$ & $(13.10-16.49)$ \\
Females & $12.34 \pm 0.95$ & $5.39 \pm 0.81$ & $14.38 \pm 0.72$ \\
& $(9.66-14.95)$ & $(3.28-7.72)$ & $(12.65-15.94)$ \\
\hline
\end{tabular}


Table 3: Differences in liver dimensions between males and females

\begin{tabular}{lcc}
\hline & \multicolumn{2}{c}{ Statistical output } \\
\cline { 2 - 3 } Liver lobes & Mean difference & $\rho$-value \\
\hline Right lobe & 11.68 & 0.000 \\
Left lobe & 4.57 & 0.000 \\
Cranio-caudal & 13.68 & 0.000 \\
\hline
\end{tabular}

Table 4: Correlation of liver dimension with anthropometric variables in male subjects r: correlation coefficient, $\rho$ : significance

\begin{tabular}{|c|c|c|c|c|c|c|c|c|c|c|}
\hline \multirow{3}{*}{$\begin{array}{c}\text { Liver } \\
\text { variables }\end{array}$} & \multicolumn{8}{|c|}{ Demographic variables } & & \\
\hline & \multicolumn{2}{|l|}{ Age } & \multicolumn{2}{|c|}{ Height } & \multicolumn{2}{|c|}{ Weight } & \multicolumn{2}{|c|}{ BMII } & \multicolumn{2}{|c|}{ BSA } \\
\hline & $\mathbf{r}$ & $\rho$ & $\mathbf{r}$ & $\rho$ & $\mathbf{r}$ & $\rho$ & $\mathbf{r}$ & $\rho$ & $\mathbf{r}$ & $p$ \\
\hline Right lobe & 0.45 & 0.000 & 0.82 & 0.25 & 0.23 & 0.001 & 0.20 & 0.004 & 0.23 & 0.001 \\
\hline Left lobe & 0.08 & 0.27 & -0.001 & 0.98 & 0.44 & 0.000 & 0.47 & 0.000 & 0.38 & 0.000 \\
\hline Cranio-caudal & 0.52 & 0.000 & 0.140 .0 & 048 & 0.35 & 0.000 & 0.29 & 0.000 & 0.35 & 0.000 \\
\hline
\end{tabular}

Table 5: Correlation of liver dimensions with anthropometric variables in female subjects r: correlation coefficient, $\rho$ : significance

\begin{tabular}{|c|c|c|c|c|c|c|c|c|c|c|}
\hline \multirow{2}{*}{$\begin{array}{c}\text { Liver } \\
\text { variables }\end{array}$} & \multicolumn{2}{|r|}{ Age } & \multicolumn{2}{|c|}{ Height } & \multicolumn{2}{|c|}{ Weight } & \multicolumn{2}{|c|}{ BMII } & \multicolumn{2}{|c|}{ BSA } \\
\hline & $\mathbf{r}$ & $\rho$ & $\mathbf{r}$ & $p$ & $\mathbf{r}$ & $\rho$ & $\mathbf{r}$ & $p$ & $\mathbf{r}$ & $p$ \\
\hline Right lobe & 0.49 & 0.000 & 0.65 & 0.37 & 0.40 & 0.000 & 0.38 & 0.000 & 0.40 & 0.000 \\
\hline Left lobe & 0.18 & 0.01 & 0.15 & 0.03 & 0.33 & 0.000 & 0.27 & 0.000 & 0.34 & 0.000 \\
\hline $\begin{array}{l}\text { Cranio- } \\
\text { caudal }\end{array}$ & 0.50 & 0.000 & 0.09 & 0.20 & 0.37 & 0.000 & 0.34 & 0.000 & 0.37 & 0.000 \\
\hline
\end{tabular}




\section{Discussion}

The findings of the current study as shown in Table 1 are almost similar to the findings of the studies conducted by Tarawneh et al. (2010) and Page | 3861 Kheiralla et al. (2016) that reported a mean value of $41.1 \pm 16.1$ years for males' $37.8 \pm 13.7$ years in females and 32.5 years for males and 38.8 years in females. The findings of the study as shown in Table 1 are similar to the findings of the studies conducted by Kheiralla et al. (2016); Singh et al., (2017) that showed male subjects have greater height compared to females despite the differences in the study locations (Saudi and India). The findings of the study as shown in table 1 are also similar to the findings of the study conducted Kheiralla et al. (2016) that reported a mean weight of $65.5 \mathrm{Kg}$ for males and $64.4 \mathrm{Kg}$ for females. The findings of the study as shown in table 1 are similar to the findings of the study conducted by Tarawneh et al. (2010) that reported BMI of 24.30 in males and 23.4 in females. However, the findings of the study as shown in Table 1 are contrary to the findings of the study conducted by Singla et al. (2017) that reported the BMI to be $18.5 \mathrm{~kg} / \mathrm{m} 2-24.9 \mathrm{~kg} / \mathrm{m} 2$. Furthermore, the findings of the study as shown in Table 1 are similar to the findings of the studies conducted by Tarawneh et al. (2010); Ozmen et al, (2018) that reported BSA values slightly higher than the current study. The possible reason may be as a result of the heights in the two studies greater than the current finding. The AP diameter of the right lobe shown in Table 2 from the current study finding is higher than those reported by Niederau et al. (1983), differences in the findings might be due to geography and duration at which the research was conducted. The mean cranio-caudal dimensions of the right liver lobe as shown by this study are $14.99 \pm 0.74 \mathrm{~cm}$ in males and $14.38 \pm 0.72 \mathrm{~cm}$ in females as shown in Table 2 , the findings were close to the findings reported by Kratzer et al. (2003), who reported the mean size to be $14.5 \pm 1.6 \mathrm{~cm}$ in males and $13.5 \pm 1.7$ $\mathrm{cm}$ in female subjects, the methods used in the two studies were the same, this might be the possible reason for the agreement, while study population and design might be the possible reasons for disagreement with other studies. The findings of the study are contrary to the findings of the study conducted by Mittal et al. (2010) who reported the left liver lobe to be $9.28 \pm 0.85 \mathrm{~cm}$ for male subjects and $9.17 \pm 1.03 \mathrm{~cm}$ in female subjects, the differences might be attributed to the right lobe dimension recorded by Mittal et al. (2010) which was also less than what was reported by the current finding. The findings of the current study show significant differences between AP diameters of the right lobe, Cranio-caudal dimensions of the right liver lobe and AP diameters of the left lobe in males and females $(\rho<0.05)$ as shown in Table 3 , this is in agreement with the findings of the study reported by (Kratzer et al. 2003; Udoaka et al. 2013; Patzak et al., 2014; Ozmen et al., 2018). However, a study conducted by Kangasa et al. (2018) found that there was no statistical significant difference between liver sizes in males and female. Furthermore, the findings of this study showed a significant weak positive correlation between Cranio-caudal dimension and height in males $(r=0.14, \rho=0.048)$ as shown in Table 4. This was similar to findings by Kheiralla et al. (2016). However, the findings show no significant weak correlation between the height the right lobe $(r=0.092, \rho=0.204)$ as shown in table 4, this was contrary to the findings of the study reported by Kheiralla et al. (2016), this might be due to differences in mean height between the two studies. Age in females showed a significant moderate positive correlation with the right lobe and Cranio-caudal dimensions $(r=0.49, \rho<0.05)$ and $(r=0.50, \rho$ $<0.05)$ respectively as shown in table 5 . In the male a moderate positive significant correlation is shown between the age and cranio-caudal size of the liver $(\mathrm{r}=0.52, \rho<0.05)$, as shown in Table 4 , this finding differs from those reported by 
Ozmen et al. (2018) who showed that there was no significant correlation between liver size and age among males $(r=0.034, \rho=0.535)$. The findings of the study show moderate positive correlation between Cranio-caudal size and AP

Page | 3862 diameters of the right liver lobe and weight in males $(r=0.40, \rho<0.05)$ and $(r=0.45, \rho<0.05)$ respectively as shown in Table 4 . This is in line with the studies conducted by (Tarawneh et al. 2010; Ozmen et al. 2018). BMI showed a moderate but significant correlation with a left liver lobe in males $(r=0.47, \rho<0.05)$ as shown in Table 4, this is almost close to findings of the study conducted by Ozmen et al. (2018) and contrary to the findings of the study conducted by (Udoaka et al., 2013). BSA on the other hand showed a moderate significant correlation with a right lobe in female subjects in the order $(r=0.40$, $\rho<0.05$ ) and showed a positive, but weaker and significant correlation with other liver measurements in both males and females $(\rho<$ 0.05 ) as shown in Table 5. This is in agreement with the findings of (Tarawneh et al.,2010).

\section{Conclusions}

Liver size is affected by many variables depending on geographical location, race and ethnicity. Our study has provided a reference value to evaluate liver sizes during assessment for any counterintuitive enlargement, liver dimensions were significantly higher in males compared to females, also age and weight in both genders show a significant positive correlation with liver dimensions.

\section{Acknowledgement}

We acknowledged the research and ethics committee of the Kano State Ministry of Health for giving us the ethical approval to conduct the research in the state. We also acknowledged the Chief Medical Director of the Muhammadu Buhari Specialist and the Head of the Department of radiology for their full support during the study. Furthermore, the Directors of the two private centers are well acknowledged for their full support and cooperation.

\section{Competing interests}

Authors have declared that no competing interests exist.

\section{References}

Ahidjo, A. and Tahir, A. (2012). Handbook of Introductory Abdominal Ultrasound for West Africa $\left(1^{\text {st }}\right.$ ed.). Borno: NTEC Specialist Limited.

Barrett, K. E. (2012). Ganong's review of medical physiology $\left(24^{\text {th }}\right.$ ed.). New york: McGraw-Hill Medical.

Childs, J. T. (2014). Methods of Determining the Size of the Adult Liver Using 2D Ultrasound. Journal of Diagnostic Medical Sonography, 30(6), 296-306.

Kangasa, N., Kabelenga, E., Siziya, S., Mwanakasale, V. and Malama, A. (2018). Sonographic Measurement of Liver Size in Adult Zambian at the Copperbelt University Micheal Chilufya Sata School of Medicine. International Journal of Current Innovations in Advanced Research, 1(7), 37-41.

Kheiralla, O., Babikr, W. and Mohamed, A. (2016). Sonographic Average Value Of Normal Liver Span Among Saudi Adults Referred To Najran University Hospital. IOSR Journal of Dental and Medical Sciences, 15(5), 27-34.

Kok, T., Van der jagt, E. J., Haagsma, E. B., Bijleveld, C. M., Jansen, P. L. and Boeve, W. J. (1999). The value of Doppler ultrasound in cirrhosis and portal hypertension. Scandinavian Journal of Gastroenterology. Supplement, 230, 8288. 
Kratzer, W., Fritz, V., Mason, R. A., Haenle, M. M. and Kaechele, V. (2003). Factors affecting liver size: a sonographic survey of 2080 subjects. Journal of Ultrasound in Medicine: Official Journal of the Page | 3863 American Institute of Ultrasound in Medicine, 22(11), 1155-1161.

Mittal, R. and Chowdhary, D.S. (2010). A Pilot Study Of The Normal Measurement Of The Liver And Spleen By Ultrasonography In The Rajasthani Population. Journal of Clinical and Diagnostic Research; 4(4), 2733-2736.

Moore, K. L., Dalley, A. F. and Agur, A. M. R. (2013). Clinically Oriented Anatomy. (6 ${ }^{\text {th }}$ ed.). Philadelphia: Lippincott Williams \& Wilkins.

Niederau, C., Sonnenberg, A., Müller, J. E., Erckenbrecht, J. F., Scholten, T. and Fritsch, W. P. (1983). Sonographic measurements of the normal liver, spleen, pancreas, and portal vein. Radiology, 149(2), 537-540. Odegaard, S., Gilja, O. and Gregersen H. (2005). Basic and New Aspect of Gastrointestinal Ultrasonograph. Singapore: World Scientific Publishing Company.

Özmen, Z., Aktaş, F., Özmen, Z., Almus, E. and Demir, O. (2018). Ultrasound measurement of liver longitudinal length in a North Anatolian population: A community- based study. Nigerian Journal of Clinical Practice, 21(5), 653.

Patzak, M., Porzner, M., Oeztuerk, S., Mason, R. A., Wilhelm, M., Graeter, T., Kratzer, W.,
Haenle, M. M., Akinli, A. S. and the EMIL Study Group. (2014). Assessment of liver size by ultrasonography: Sonographic Liver Size. Journal of Clinical Ultrasound, 42(7), 399-404.

Singh, T. (2017). Clinical and Sonographic Estimation of Liver Span in Normal Healthy Adults. International Journal of Medical Research \& Health Science, 6(1), 94-97.

Singla, B., Singh, T., Jain, M., Savani, S. and Oli, S. (2017). Effect of Anthropometrical Measurements on Liver Span Using Ultrasonography. International Journal of Medical Research \&Health Science, 6(9), 5-10.

Tarawneh, E. S., Hadidy, A. M., Haroun, A. A., Mahafza, W. S., Samara, O. A., Arafeh, F. M., and Alsharif, A. A. (2010). Ultrasound Measurement of Liver Span in Jordanian Adults: A Preliminary Experience. Jordan Medical Journal, 43(3), 197-204.

Udoaka, A. I., Enyi, C. and Agi, C. E. (2013). Sonological Evaluation of the Liver, Spleen and the Kidneys in an Adult Southern Nigerian Population. Asian Journal of Medical Sciences, 5(2), 33-36. 